\title{
OS CONCEITOS DE GESTÃO E ADMINISTRAÇÃO: APLICAÇÃO AO ESTUDO DAS GESTÕES DOS DIRETORES DA FACULDADE DE CIÊNCIAS MÉDICAS DA UNIVERSIDADE ESTADUAL DE CAMPINAS
}

\author{
Ivan Luiz Martins Franco do Amaral \\ Everardo Duarte Nunes \\ Universidade Estadual de Campinas, Brasil.
}

\begin{abstract}
Resumo
Neste artigo se descreve a metodologia utilizada na elaboração de um projeto que analisa as gestões da Faculdade de Ciências Médicas da Universidade Estadual de Campinas, durante o período de 1963-2014. Parte-se da conceituação de gestão e administração e da caracterização das diferentes teorias de administração. A principal referência em termos de metodologia é a metodologia quadripolar - epistemológica, teórica, morfológica e técnica - elaborada por Bruyne, Herman e Schoutheete (1977). Para ilustrar essa abordagem teórica e metodológica é apresentada uma breve análise da primeira gestão (1963-1969). Concluiu-se que a metodologia é adequada e há possibilidade de aplicação ao estudo das gestões que se seguiram a primeira.

Palavras-chave: gestão, administração, gestão institucional, escolas médicas, Faculdade de Ciências Médicas da Unicamp.
\end{abstract}

\section{THE CONCEPTS OF MANAGEMENT AND ADMINISTRATION: APPLICATION TO THE STUDY OF THE MANAGEMENTS OF THE DIRECTORS OF THE STATE UNIVERSITY OF CAMPINAS FACULTY OF MEDICAL SCIENCES}

\begin{abstract}
This article describes the methodology used in the elaboration of a project that analyzes the managements of the State University of Campinas Faculty of Medical Sciences during the period 1963-2014. It starts from the concept of management and administration and the characterization of different theories of administration. The main reference in terms of methodology is the quadripolar methodology - epistemological, theoretical, morphological and technical - elaborated by Bruyne, Herman and Schoutheete (1977). A brief analysis of the first management (1963-1969) is presented to illustrate this theoretical and methodological approach. The authors conclude that the methodology is adequate and there is possible application to the study of the managements that followed the first one.

Key-words: management, administration, institutional management, medical schools, Faculty of Medical Sciences of Unicamp.
\end{abstract}




\section{Introdução}

A s preocupações sobre os conceitos de gestão e administração de instituições universitárias surgiram no momento em que elaborava, junto com o orientador, o projeto de dissertação de mestrado no qual se aborda a gestão dos diretores da Faculdade de Ciências Médicas da Universidade Estadual de Campinas FCM/Unicamp -, desde a sua primeira diretoria em 1963 até 2014, totalizando catorze gestões.

Interessante que ao pesquisar a base de dados Scielo - escola médica + gestão fomos surpreendidos que houvesse somente dez referências, incluindo uma que repetia a informação em português e inglês três vezes, com essas palavras, período 2013/14. Assim mesmo, somente uma referia-se explicitamente sobre a questão, as demais tratavam de diversas questões de ensino, inovações curriculares, métodos ativos. Esta referência, até certo ponto, tranquilizou-nos, pois seu autor Márcio José de Almeida (2008), médico, com doutorado em Saúde Pública e especialista em pesquisas de educação médica e formação de recursos humanos em saúde, comenta que "a administração universitária, em especial a gestão da escola médica, não é temática reconhecida e valorizada pela comunidade acadêmica. No entanto, o desenvolvimento da formação médica depende, em grande parte, de boas práticas de gestão", ressaltando que "são importantes não apenas para o bom desenvolvimento das atividades acadêmico-administrativas, mas, em especial, para conseguir sucesso nas iniciativas de mudança na formação médica e dos demais profissionais de saúde" (p. 202).

Com as palavras escola medica + administração há somente quatro referências, incluindo a citada acima de Almeida. Verificamos que o tema é pouco explorado embora se revista de especial importância para os estudos das instituições universitárias no campo da saúde. Acrescente-se que as conceituações de gestão e administração, no quadro geral do conhecimento, ainda são atravessadas por vários questionamentos.

Dessa forma, situamos como principais pontos deste artigo as perguntas: como caracterizar essas noções? Quais são os seus significados? Como se situam esses significados frente às diversas teorias de administração? Como isso se junta ao problema de estudar a gestão em determinadas instituições universitárias, no caso as faculdades de medicina? Como trabalhar essa temática em um caso concreto? Ao planejar responder essas questões abriu-se toda a problemática metodológica da pesquisa, que, também, é apresentada neste momento. De outro lado, a fim de ilustrar as ideias de gestão e administração aqui desenvolvidas, apresentamos, como exemplificação, uma breve análise da primeira gestão da FCM/Unicamp - 1963-1969.

\section{Conceituando gestão, administração e gestão administrativa}

Dias (2002), em detalhada análise, mostra que há diferenças contextuais e de aplicação entre os termos gestão e administração. Para o autor "a tarefa é árida principalmente no que tange à delimitação da gestão. As várias obras pesquisadas não são definitivamente esclarecedoras sobre a questão e os mais diversos autores não demonstram uma certeza sobre o tema" (p. 3). Retomando esse artigo e outras fontes bibliográficas, sintetizamos alguns pontos sobre a questão conceitual. Incialmente, Dias (2002) aponta que "os dicionários da língua portuguesa trazem as duas palavras- gestão e administração - como sinônimos entre si. Mostram que suas origens vêm do latim, e 
mesmo possuindo estruturas diferentes, são traduzidas de formas semelhantes enquanto sentido de ação" (p. 3). O autor destaca esta questão citando o trabalho de Ferreira (1997) questionando gestão ou administração em diversas línguas e comparando com o português. Haveria "um ponto comum para os outros idiomas, ou seja, não há uma clara definição entre os termos" (p. 3). Dias (2002) comenta que o autor, "em sua análise, [dispõe] gestão como mais apropriado para ação sobre o bem privado, e administração, o correto sobre o bem público". Mas Ferreira (1997) "utiliza as duas palavras de forma indiscriminada, prova que suas explicações não esgotaram o assunto, e deve-se ressaltar que não era intenção do autor exauri-lo, devido às poucas linhas dedicadas à questão" (p. 3).

Nessa linha de discussão Santos, Santos e Braga (2014) apresentam trabalho no qual procuram "analisar a trajetória da administração, na condição de campo científico, refletindo sobre seus percursos e percalços, principalmente sobre a problemática epistemológica de estarmos diante de um saber que sequer tem claramente definido o seu objeto de estudo" (p. 2). O trabalho situa o desenvolvimento teórico da administração e destaca a gestão e os estudos organizacionais. Citam o trabalho de Cunha (2000), quem afirma que

a ciência organizacional é entendida como um dos domínios disciplinares que ajudam a formar o território multidisciplinar que é a gestão. Ou seja, nem tudo o que é gestão é do domínio da ciência organizacional, mas toda ciência organizacional pode ser entendida como podendo ser abarcada por uma ciência de gestão que demonstre preocupações não apenas aplicadas, como também, teóricas. (p. 47)

Grilo (1996) apresenta uma visão geral e bibliográfica sobre a teoria da gestão. Na revisão de Grilo (1996) observa-se que a questão aparece, sobretudo, a partir do século 19 quando emergiu "a necessidade de sistematizar e orientar a forma de gerir as organizações econômicas” (p. 18).

O desenvolvimento teórico da administração ocorreu no século 20 , desde os clássicos trabalhos de Taylor (1903), Fayol (1916), Weber (1909), e uma série de desdobramentos, como é exposto por Oliveira, Moraes, Dourado (2006) considerando a ênfase, as características e principais enfoques de cada teoria. As ênfases se distribuem em cinco grupos: nas tarefas - Taylor - racionalizando e operacionalizando o trabalho; na estrutura - Fayol - formalizando e criando as funções do administrador; teoria neoclássica (1954) - eclética, pragmática e ênfase nos objetivos; teoria da burocracia - weberiana, ênfase na racionalidade organizacional; teoria estruturalista (1947) com base na sociologia organizacional, múltipla abordagem, tanto formal quanto informal, intra e interorganizacional; nas pessoas - teoria das relações sociais (1932), ênfase na motivação, liderança, comunicação, dinâmica de grupo; teoria do comportamento organizacional (1957), ênfase na teoria das decisões; teoria do desenvolvimento organizacional (1962) enfatizando a mudança organizacional planejada; no ambiente teoria estruturalista (1947), ênfase na análise intra-organizacional e ambiental, abordagem de sistema aberto; teoria da contingência (1972), a análise ambiental é imperativa; na tecnologia - teoria da contingência (1972) a análise da tecnologia é imperativa. 


\section{Gestão em saúde e gestão institucional}

Além dos conceitos vistos anteriormente precisamos situar de forma mais clara como esses conceitos são apreendidos pelo campo da saúde e acrescentar uma outra noção que nos parece básica para o entendimento da gestão em faculdades de Medicina: a de gestão institucional.

Quando revisamos gestão em saúde verificamos que o quadro conceitual não é muito diferente do mostrado anteriormente visto, no qual são encontrados posicionamentos diversos em relação ao seu significado. Diga-se, ainda, que gestão aparece na interface com a noção de planejamento. Nesse sentido, Rivera, Artmann (2010) oferecem subsídios que fundamentam esta nossa afirmação, assim como outros diversos estudos no campo do planejamento em saúde, pois, além desta citação, a base Scielo apresenta 156 referências (1998-2014) quando acessamos gestão e planejamento em saúde, sendo que gestão em saúde apresenta um total de 1.330 referências. Não vamos realizar uma análise dessas referências, visto que no aspecto que nos interessa, o filtro da Scielo apresenta uma única referência.

Essas observações são importantes, mas como o nosso foco é a gestão, trabalhamos um outro conceito: gestão institucional.

Para isso recorremos à apresentação de Masetto (2011) quando diz que "estamos denominando gestão institucional a gestão da missão e dos recursos de uma instituição de ensino superior. Corresponde ao processo de administrar a dinâmica de um sistema de formação profissional como um todo, articulando diretrizes e políticas educacionais com os recursos necessários à sua realização"(s/p). Para o autor a gestão integrada missão e recursos - opera em três níveis: formação de profissionais, desenvolvimento da pesquisa e prestação de serviços à comunidade, níveis que já havíamos pensado para a descrição e análise das gestões dos diretores de uma faculdade de ciências médicas. Lembramos, como assinala Almeida (2008), a importância que tem as "boas práticas de gestão" tanto para o desenvolvimento das atividades acadêmico-admistrativas, como para "conseguir sucesso nas iniciativas de mudança na formação médica e dos demais profissionais de saúde", reafirmando "as vivências, seus desafios e dilemas" nos "estudos na intersecção das áreas de administração e educação médica” (p. 203).

Ao trazermos a pesquisa para o interior de uma instituição de ensino, com propósitos específicos - o ensino médico - não podemos esquecer que ela faz parte do sistema de ensino superior. Assim sendo, como analisam Franco, Afonso, Bordgnon (2012),

no caso da gestão da educação superior considera-se que esta envolve decisões estratégicas que refletem os modelos de relacionamento entre as instituições/sistema de IES no nível conceitual (documentos) e/ou práticas do processo decisório e que elas revelam uma racionalidade prevalente. $\mathrm{O}$ conceito subjacente de gestão envolve instituições onde a educação tem lugar e seu(s) objetivo(s), compreendem pressuposições sobre a pesquisa/ensino/extensão e princípios de organização. (p. 88)

\section{Pesquisando a gestão em uma situação concreta}

Ao iniciarmos esta pesquisa a perspectiva não foi a de centralizá-la a priori em determinadas escolas de pensando sociológico: positivistas, compreensivas, funcionalistas, estruturais, estruturalistas. Presumimos que, individualmente, nenhuma 
delas poderia fonercer um quadro teórico único de referência. Após termos tratados dos conceitos básicos do trabalho, sentimos a necessidade de esclarecer as questões metodológicas da pesquisa.

Assim, adotamos a proposta de Bruyne, Herman, Schoutheete (1977) e os eixos da prática metodológica: os polos epistemológico, teórico, morfológico e técnico. De um modo geral, os quatro polos exercem funções controladoras sobre os objetivos em qualquer pesquisa social: o epistemológico controla a própria concepção e construção do conhecimento científico; o teórico guia a elaboração de hipóteses e construção de conceitos; o morfológico estrutura a formulação do objeto científico, configurando ou modelando as interações entre conceitos, variáveis eventos e conexões históricas da realidade estudada; o técnico controla a coleta dos dados, a observação, o relato dos fatos.

Nesta pesquisa esses polos oferecem orientações que são abaixo apresentadas e que subsidiam a conformação da pesquisa, vista, também, como uma construção teórica. Esta abordagem tem sido amplamente utilizada em diferentes campos de conhecimento, saúde coletiva, educação e administração. Por exemplo, no campo da administração Moraes; Mariano; Macedo; Mancebo (2012) estudam o empreendedorismo, analisando os artigos publicados nos eventos da Associação Nacional de Pós-Graduação e Pesquisa em Administração e como se situam frente aos quatro polos. Apontam que "nossas maiores contribuições se dão no polo técnico, aquele relacionado à coleta dos dados e são inúmeros os estudos de caso encontrados. Na realidade é para onde converge a maioria das pesquisas empíricas que abordam o empreendedorismo e seus temas relacionados" (p. 546).

\section{a. Polo epistemológico}

Na expressão de Bruyne, Herman, Schoutheete (1977) constitui "o motor interno, obrigatório, na investigação do pesquisador" (p. 44) que orienta a construção do objeto da investigação e dos métodos, para além do objeto percebido, no caso das gestões os atos administrativos e suas publicações oficiais, as construções e suas placas com os fundadores e datas, os arquivos e seus documentos, etc. Situamos esta pesquisa no quadro geral da pesquisa qualitativa documental, mas, dialeticamente, "pens[ando] a relação do pesquisador com seu objeto de conhecimento, das ciências com o real" (p. 51), procurando captar semelhanças, diferenças e contradições que se desenvolvem temporalmente.

\section{b. Polo teórico}

A proposta deste trabalho de descrever e analisar gestores, uma instituição, os contextos históricos, sociais e políticos numa trajetória de cinco décadas na administração de uma instituição pública de ensino levou-no a não se fixar em uma determinada e única teoria sociológica. Isso não retira a necessidade de quadros de referência. Podemos dizer que esses quadros tensionam tanto o papel dos gestores e das relações com os sistemas educacionais, ciência e tecnologia, sistema de saúde mais próximos de um esquema de referência funcionalista, até às relações econômicas, políticas, culturais, mais próximas de um marco estrutural. 
De outro lado, não se pode esquecer que a própria área de administração ou gestão desenvolveu ao longo do tempo um quadro teórico que buscou suas fundamentações na economia, sociologia, ciência política e administração, para citarmos alguns campos de conhecimento. Pensamos que as diferentes ênfases, de acordo com cada teoria administrativa, posta por Oliveira, Moraes, Dourado (2006), poderão orientar a possibilidade de visualizarmos como as administrações de uma instituição de ensino se posicionaram frente às demandas estruturais e relacionais, ambientais e tecnológicas.

\section{c. Polo morfológico}

Bruyne, Herman, Schoutheete (1977) são bastante diretos quando afirmam que "ao polo morfológico compete unicamente a função metodológica de fornecer uma configuração, uma arquitetônica" (p. 162). Os autores também assinalam que o "espaço morfológico pode se desdobrar em vários planos para acolher a construção de modelos teoréticos que se referem a modelos materiais que descrevem estado de coisas" (p. 163). Assim, podemos apresentar a totalidade do material empírico - as gestões como um processo histórico -, como criar tipologias que atravessam determinados tempos históricos. Os autores dos polos referem-se à "totalidade global versus totalidade parcial" (p. 164). Em nossa pesquisa o quadro de análise toma como referencial teóricometodológico a análise do discurso, segundo a proposta de Michel Foucault (1972).

Frente ao material documental - discurso disperso - na acepção de Foucault, procura-se analisar:

a. os elementos que compõem o discurso - regras de formação -, desvendando seus objetos - que aparecem, coexistem e se transformam, no que é denominado espaço comum do discurso; os diferentes tipos de enunciação que podem permear os discursos; os conceitos e suas formas de aparecimento e transformação, que num campo discursivo podem estar relacionados a um sistema comum; os temas e teorias que podem estar presentes ou terem sido excluídos,

b. a formação discursiva com suas rupturas e descontinuidades.

Desta forma, o trabalho configura uma pesquisa com orientação qualitativa, uma vez que, busca compreender os significados e características situacionais. Voltando a Foucault (1972), toma-se como dimensão importante na análise que

qualquer enunciado se encontra assim especificado: não existe enunciado em geral, enunciado livre, neutro e independente; mas, sempre um enunciado fazendo parte de uma série ou de um conjunto, desempenhando um papel no meio dos outros, apoiando-se neles e se distinguindo deles: integra-se sempre em um jogo enunciativo, em que tem sua parte, por ligeira e ínfima que seja. (p. 124)

d) Polo técnico

Como enunciado acima, trata-se de uma pesquisa qualitativa, classificada por Bruyne, Herman, Schoutheete (1977) como de análises documentais. Considera-se como principal material a documentação gerada pelas administrações: planos diretores; relatórios de gestão; atos administrativos, boletins informativos, teses e dissertações sobre a Faculdade de Ciências Médicas; discursos dos diretores, vida funcional e 
memorial dos diretores. Acrescente-se a documentação bibliográfica básica sobre as políticas de ensino superior no Brasil (1963-2014) e pesquisas que tratam da história da Unicamp e da Faculdade de Ciências Médicas, incluindo as específicas sobre ensino e assistência à saúde.

\section{Contextos históricos e as origens da Faculdade de Ciências Médicas e da Unicamp}

Em realidade, a pesquisa sobre as administrações é parte integrante da história da Faculdade que por sua vez não pode se abstrair de eventos sociais, históricos, políticos, educacionais e sanitários gerais ao país ocorridos nos diversos momentos dessas administrações. Destacamos os seguintes aspectos: demográfico, sanitário e social, político e econômico, políticas de saúde, educação médica a partir de 1960, associados a informações marcantes dos períodos, relacionados a eventos locais na história de Campinas, da Unicamp e da Faculdade de Ciências Médicas.

Exemplificamos com um estudo preliminar da primeira gestão como pretendemos encaminhar a nossa narrativa.

A primeira gestão: criando uma estrutura administrativa e de ensino - Dr. Antonio Augusto de Almeida (1963-1969)

O dr. Antonio Augusto de Almeida (1903-1975) foi o primeiro diretor da FCM/Unicamp e exerceu seu mandato de 1963 a 1969. Sua gestão confunde-se com os primeiros anos da Faculdade de Medicina, no enfrentamento da sua organização e estabelecimento de como administrar uma instituição de nível superior.

Dr. Almeida faz parte da longa história de quase três décadas que antecede a criação da Faculdade de Medicina de Campinas na qual estão presentes jornalistas, como Luso Ventura, médicos, a sociedade de medicina e cirurgia, a sociedade civil e suas organizações. Em 1960, na fase de quase concretização desse longo percurso, ao assumir presidência da Sociedade de Medicina e Cirurgia de Campinas, o patologista Roberto Franco do Amaral "faz uma apelo para que o Conselho de Entidades retorme suas atividades, dando prosseguimento a um novo e intenso período de reivindicação" (Faculdade de Ciências Médicas, 2013, p. 25). Nesse momento Franco do Amaral indica o dr. Almerida como "representante da luta pela instalação da Faculdade de Medicina e novas entidades aderem ao movimento pró faculdade, que cresce de 18 para 23 associações de classe" (p. 25). Três anos depois, em fevereiro de 1963, o dr. Almeida seria nomeado pelo professor Cantídio de Moura Campos, ex-diretor pro tempore da Faculdade de Medicina e agora reitor da Universidade de Campinas, diretor da Faculdade de Medicina. Moura Campos também nomeia o professor Walter Augusto Hadler pra a Cadeira de Hisitologia e Embriologia.

Numa sequencia de fatos foi realizado o primeiro vestibular, para o qual se inscreveram 1.592 candidatos para as 50 vagas existentes e no mês de maio foi instalada solenemente a Faculdade, com a aula inaugural realizada no dia 20 pelo reitor da Universidade de São Paulo, professor Antônio Barros de Ulhôa Cintra. No mesmo mês foi 
instalado o Conselho de Curadores da Universidade, sendo sua primeira reunião em 8 de maio. Em agosto o governo paulista nomeou para a função de reitor o professor Mário Degni, que tomou posse em outubro. Sua gestão foi até setembro de 1965. Em 1966 assumiu a reitoria o professor Zeferino Vaz.

Lembre-se que a Universidade Estadual de Campinas foi legalmente criada, como entidade autárquica, pela lei n. 7.655, de 28 de dezembro de 1962, incorporando a Faculdade de Medicina de Campinas, criada como instituto de ensino superior isolado pela lei n. 4.966 em 25/11/1958, como previsto no projeto. Cantídio de Moura Campos foi designado como reitor, assumindo o cargo em 13 de janeiro do ano seguinte e exercendoo por oito meses, com a responsabilidade promover a instalação da nova universidade.

Mineiro da cidade de Oliveira, o professor Antonio Augusto de Almeida nasceu em 11 de abril de 1903 e com vinte e três anos graduou-se em Medicina pela Faculdade de Medicina da Universidade de Minas Gerais. Em 1956 obteve o título de livre docente em Clínica Oftalmológica pela Faculdade de Medicina da Universidade de São Paulo, com o trabalho intitulado $A$ esclerectomia posterior no descolamento da retina (Almeida, 1954). $\mathrm{Na}$ tese revela a sua opção pela oftalmologia:

A oftalmologia foi o alvo que procuramos atingir ao iniciar o curso médico. Dentro da oftalmologia a parte cirúrgica mereceu a nossa predileção. Verdadeiro mestre, que sabia ensinar estimular vocações, J. Santa Cecília adentrou-nos na oftalmologia desde os bancos acadêmicos. Explica-se assim a escolha do assunto cirúrgico para a presente dissertação. (p. 9)

Ao assumir a diretoria da Faculdade de Medcina o Dr. Almeida, em 1963, além da sua tese, era autor de 40 trabalhos científicos publicados em diversos periódicos nacionais, desde 1930.

Em 1974 publicou seu primeiro livro dedicado ao apoio didático resultado do seu trabalho junto aos alunos de graduação em medicina da Unicamp: "das apostilas por mim elaboradas, no primeiro ano do curso, na Faculdade de Ciências Médicas da Universidade Estadual de Campinas, ousei imprimir o que ensino aos jovens" (Almeida, 1974, p. III ).

A Faculdade da Unicamp está entre as quatro faculdades de medicina criadas em 1963: a da Universidade Estadual Paulista em Botucatu; a da Universidade Católica de Pelotas e a da Santa Casa de São Paulo. Com essas novas faculdades atingia-se, nesse ano, o número de 33 faculdades criadas de 1808-1963. São instituições que trazem em suas histórias as efervências e turbulências dos anos 1960 e em suas histórias particulares os eventos locais que estão em suas origens.

No mundo esses anos serão sempre citados, entre outros motivos, pela contracultura, revolução cubana, construção do muro de Berlim, envio do primeiro homem a viajar pelo espaço e do primeiro a pisar na lua, movimentos estudantis, feministas e das minorias, da música dos Beatles, uso da informática para fins comerciais e lançamento do primeiro computador, etc.

No Brasil, os anos 1960 são marcados pelas transformações político-institucionais com a renúncia do presidente Jânio Quadros, após dez meses de governo, outubro de 1960-agosto de 1961, e a presidência do vice-presidente João Goulart, que foi deposto por golpe militar em 1964. Assim, a primeira gestão da Faculdade, como todas as que a sucederam até 1985 estarão sob regime ditatorial. 
Do ponto de vista da saúde Pagliosa e Da Ros (2008) assinalam que em todo mundo, a partir dessa década, intensificam-se as críticas ao setor saúde no que se denominou a crise da medicina e evidenciaram o descompromisso com a realidade e as necessidades da população. Essa crise se refletia no Brasil que apresentava baixos indicadores de saúde: mortalidade geral de 13/1000 hab.; mortalidade infantil, 118/1000 nascidos vivos; a esperança de vida ao nascer, 52 anos; 25,9\% dos óbitos devido a infecções parasitárias; taxa de fecundidade, 6,3.

Segundo Pagliosa e Da Ros (2008, p. 496), os meios acadêmicos, instituições e fundações internacionais e associações civis não estiveram alheias às questões de saúde e criaram "intensa movimentação".

Nesse sentido, a Faculdade de Medicina da Unicamp procurou manter relações com a Organização Pan-Americana da Saúde, convênio para aquisisção de livros, em 1967, e mais tarde, em 1970, com a W. K. Kellogg Foundation. Dois outros convênios foram avaliados durante a primeira gestão: com a URSS/Banco de Desenvolvimento Econômico para aquisição de equipamentos russos de laboratório, porém, não foi concretizado pela justificativa que a universidade necessitava de equipamentos com maiores tradições e assistência técnica, e Polônia/Ministério da Educação e Cultura: US\$ 400.000,00 da denominada missão técnica polonesa para assessorar os institutos universitários com a aquisição de equipamentos didáticos (Unicamp, 1968).

Do ponto de vista das questões educacionais, são fatos relevantes a realização, em 1960, da II Conferência de Faculdades de Medicina Latino-Americanas, propondo a criação de associações nacionais voltadas ao ensino da medicina; a lei n. 4.024, de 20 de dezembro de 1961, que fixou as diretrizes e bases da educação nacional; a criação, em 1962, da Associação Brasileira de Educação Médica - Abem. Dois fatos destacam-se no panorama geral e específico da medicina nessa década: em 1968 a reforma univesitária e no mesmo ano a resolução CFE n. 8, que regulamentou o ensino médico e estabeleceu o currículo mínimo (Abem, 2015).

É interessante observar que durante toda a década, desde 1963 quando realiza o seu primeiro Congresso, até 1967, os temas da Abem (2015) refletiram problemas vivenciados pelas escolas médicas: o ensino da medicina preventiva, pedagogia aplicada à medicina: internato e residência, formação de pessoal paramédico, ensino da psicologia, hospital de ensino, integração do ensino básico-profissional. No final da década dois congressos tiveram como temas a formação do profissional frente à realidade brasileira e o planejamento do ensino médico.

Retomando a história da Faculdade de Medicina de Campinas, em relação às atividades administrativas da primeira gestão, observamos que estiveram voltadas para a criação de condições que possibilitassem o ensino, nomeando os primeiros docentes, na então denominadas cadeiras, com suas chefias: os catedráticos. Assim, criam-se em 1963 as cadeiras de Histologia e Embriologia (Walter August Hadler), Cadeira de Anatomia (João Baptista Parolari), Cadeira de Genética (Bernardo Beiguelman); em 1964 o de departamento de Farmacologia; em 1965 os departamentos de Anatomia Patológica, Medicina Preventiva e Social (atual Saúde Coletiva) e Clínica Médica (Cirurgia é integrada 
em 1968); em 1966 os de Psicologia Médica e Psiquiatria, Tocoginecologia, Pediatria e Neurologia e a disciplina de Medicina Legal; o último departamento criado na primeira gestão foi o de Ortopedia e Traumatologia, em 1967 (Faculdade de Ciências Médicas, 1993).

Segundo Freire-Maia havia em exercício 11 professores titulares, 5 assistentesdoutores, 15 realizando serviços especializados, 1 assistente-docente, 2 realizando funções docentes e assistenciais, e 67 instrutores:

Naturalmente, a imensa maioria dos docentes é constituída por médicos,
mas também alguns outros profissionais (dentista, advogado, sociólogo,
veterinário, psicólogo, e enfermeira). Apenas 3 Professores Titulares e 6
Instrutores estão em RDIDP, mas, no todo, há 31 docentes em regime de
44 horas semanais (RDIDP ou RDP). De qualquer forma, a frequência de
docentes em Regime de Tempo Parcial (70\%). (Unicamp, 1970, p. 16)

Sem detalharmos as estruturas das disciplinas ensinadas, é necessário analisar algumas das principais características dos primeiros planos de ensino desenvolvidos quando a Faculdade iniciava as suas atividades. De um modo geral a Faculdade reproduzia as discussões que se realizaram na década de 1950 com as propostas de mudanças no clássico modelo flexneriano da primeira década dos século 20. Mesmo com inovações importantes, como a extensão do cuidado à comunidade, numa incipiente clínica de família, tentativa de integração entre os departamentos de medicina preventiva e social, ginecologia e pediatria, a introdução das ciências sociais, o ensino de história da medicina - professor Lycurgo de Castro Santos Filho, de 1965-67 - e da bioestatística professor Rubens Murilo Marques, 1966 -, podemos dizer que, de um modo geral, o modelo era tradicional, dividindo o curso em dois momentos: o ciclo básico de dois anos e o profissional de quatro anos, num sistema de disciplinas.

Relatos circunstanciados mostram que o atendimento médico assistencial era propiciado a pacientes, internados e de ambulatório, na Santa Casa de Campinas e em um bairro periférico. Trata-se do Bairro Jardim dos Oliveiras, que esteve "sob o controle direto e atuante do Departamento de Medicina Preventiva, em estreita cooperação com as autoridades estaduais da Secretaria da Saúde" (Unicamp, 1968). Nesse bairro os estudantes de Medicina estudavam conceitos sobre a historia natural da doença e aprendiam a multiplicidade de fatores econômicos, culturais e psicológicos que podem interferir na origem e evolução das doenças. No relatório do DMPS, de 1968, são destacadas, entre outras, as atividades de educação em saúde, saúde escolar, organização do clube de mães, reorganização da Sociedade Amigos do Bairro.

Atividades extra-muros também foram desenvolvidas pelo Departamento de Tocoginecologia, em convênio com a Secretaria da Saúde da Prefeitura Municipal de Campinas, e aprovadas pelo Ministério da Saúde, como a campanha de prevenção do câncer uterino.

Destacamos que a questão de administrar a recém-criada Faculdade não era apenas de formar um corpo docente e criar disciplinas, mas situar de forma adequada os espaços para as suas atividades. Criada a Faculdade a pergunta era onde desenvolver suas atividades de ensino? Foram diferentes locais. Inicialmente no prédio da Maternidade de Campinas, durante os dois primeiros anos, mas com a aproximação dos anos clínicos, e sendo despejados pela Maternidade, havia necessidade de um hospital 
para o ensino com pacientes. Nesse momento os estudantes realizam pelas ruas de Campinas uma passeata reivindicando outras instalações. Estas instalações foram o prédio secular da Santa Casa de Misericórdica e seus anexos, onde a Faculdade ficaria durante vinte anos, de 1965 a 1985 (Faculdade de Ciências Médicas, 2013).

Em 1968, quarenta e dois alunos, trinta e seis homens e seis mulheres, dos cinquenta que haviam ingressado em 1963, graduavam-se como a primeira turma da agora denominada Faculdade de Ciências Médicas da Universidade Estadual de Campinas. Como paraninfo, o primeiro diretor, o dr. Almeida, ao dirigir-se à turma de médicos e medicas, assim se expressou:

E vosso paraninfo, todo orgulhoso da escolha, de coração se associa as [escolhas] que o afeto de vossos familiares neste momento e vos lembra que, de agora em diante, pertenceis a uma classe social que sempre é examinada, criticada, seguida e que serve de exemplo a todas as condutas. [...] Da época de sua implantação, das improvisações que se fizeram necessárias, do entusiasmo que supria as deficiências, do sacrifício que substituía a pobreza, do consolo que vos trazia em todas as oportunidades e ainda ontem, de constituirdes "a turma histórica". A primeira a se matricular, a fundadora do centro, a primeira a inaugurar as disciplinas, a primeira a enfrentar problemas que surgem à medida que o curso avança. Teria sido ideal que a Faculdade tivesse sido instalada após a organização da Universidade. Teria sido muito mais fácil se tivesse havido planejamento! Mas tais e tantos os reclamos, estais lembrados, que a ordem recebida nos dias finais de fevereiro de 63 foi "Faculdade funcionando ainda este ano". Sem prédio, sem dinheiro, sem professores e sem alunos. O resto conheceis bem. Os prédios estão sendo construídos, os recursos no governo atual, que sensível à realidade brasileira, duplicou as doo ensino superior, não tem faltado. Os professores escolhidos entre os melhores e os alunos os mais cordatos, disciplinados, compreensivos e compenetrados de seus deveres. Sois hoje vitoriosos por haverdes cumprido um árduo dever. Ao vos diplomardes, sois ainda a primeira turma. Essa que passará a história, fato este que ides orgulhar-vos pelo resto de vossa vida. (Almeida, 1968, p. 3)

O Dr. Almeida finaliza a sua gestão em 30/7/1969, entregando o cargo para o Prof. Dr. Silvio dos Santos Carvalhal que será o diretor de 19/12/1969 a 7/1/1971.

No ano anterior ao término da sua gestão o país sofreria um desdobramento do golpe de 1964, a promulgação, em 13 de dezembro de1968, do Al-5, que dava poderes extraordinários ao presidente da República, para suspender garantias constitucionais, cassar direitos políticos e intervir nos municípios e Estados. Sua primeira medida foi o fechamento do Congresso Nacional, que perdurou até 21 de outubro de 1969.

Em 1969 mais uma medida de excessão atingia diretamente as universidades. No dia 26 de fevereiro foi baixado o decreto-lei n. 477, que previa a punição de professores, alunos e funcionários considerados culpados de subversão ao regime. Os professores atingidos eram demitidos e ficavam impossibilitados de trabalhar em qualquer outra instituição educacional do país por cinco anos, ao passo que os estudantes eram expulsos e ficavam proibidos de cursarem qualquer universidade por três anos. Este decreto vigorou até 1979, quando foi revogado pela lei de anistia. Somente da 
Universidade de São Paulo foram aposentados 65 professores e demitido o reitor Hélio Lourenco de Oliveira (Unicamp, 2016). Sobre a repressão na Unicamp, que atingiria professores do Departamento de Medicina Preventiva e Social, esta ocorreu na primeira metade da década de 1970 (Unicamp, 1970).

Mesmo frente a situações nem sempre favoráveis ao pleno desenvolvimento de uma instituição universitária ainda em sua infância, na expressão do jornalista Eustáquio Gomes (2006), a Faculdade de Ciências Médicas graduou, em 1969, uma turma de 61 médicos. Novos desafios abriam-se para a década de 1970.

\section{Considerações finais}

O estudo da primeira gestão da Faculdade de Ciências Médicas da Universidade Estadual de Campinas apresenta um exemplo da pesquisa em desenvolvimento que estuda catorze gestões da Faculdade.

O tema central e pilares de análise apresentados são o ensino, a pesquisa e a extensão, cotejados com alguns aspectos das políticas públicas e educacionais. $\mathrm{Na}$ perspectiva de Masetto (2011), em nossa análise, a primeira gestão está fortemente impregnada de uma missão, lutando para conseguir recursos para viabilizar um projeto educacional. Portanto, uma gestão muito mais preocupada com as tarefas e objetivos imediatos; o planejamento a médio e longo prazo seria para as próximas gestões. Isto não exclui os embates e as controvérsias num momento de pré-institucionalização da Universidade e da Faculdade de Medicina, que transcendem os documentos e aparecem em depoimentos e relatos, como os narrados por Gomes (2006).

$\mathrm{Na}$ tentativa de uma aproximação téorica ao estudo dessa gestão podemos dizer que à ela, como às seguintes, aplica-se uma análise funcionalista, pois estamos lidando com valores relacionados à profissão médica e à educação, normas: o curso médico da Faculdade de Medicina, enquanto não tivesse seus estatutos aprovados, seguiria o Regimento da Faculdade de Medicina de Ribeirão Preto da Universidade de São Paulo; papéis sociais: diretor, funcionários, estudantes, membros de comissões (Unicamp, 1970).

Lembramos que "o campo da administração surge no contexto fortemente influenciado pelo conceito de ciência comtiana e pela lógica funcionalista" (Santos, Santos, Braga, 2014, p. 20). Nesse sentido, estendemos para esta pesquisa e, em particular, para o estudo da primeira gestão, a proposta de Pereira (2006) quando analisou alguns trabalhos da medicina social na perspectiva funcionalista. Para este sociólogo,

o emprego da análise funcionalista é indispensável para a produção de conhecimentos sociológicos sobre conexões funcionais e relações sincrônicas numa dada sociedade ou em seus subsistemas. Tal conhecimento diz respeito aos conhecimentos e condições sociais que tornarm possível o ajustamento recíproco de agentes sociais, individuais ou coletivos, numa determinada situação, bem como o exercício de funções por parte de instituições ou a realização de processos sociais com efeitos definidos no asseguramento da organização e continuidade dos sistemas globais ou parciais. (p. 115)

De outro lado, a utilização de diversas fontes documentais e bibliográficas permitiu uma aproximação metodológica utizando diversos discursos, como proposto por Foucault (1972), inclusive de trazer à tona o contexto extra-discursivo dos substratos sociais,

\begin{tabular}{|l|l|l|l|l|l|}
\hline Regae: Rev. Gest. Aval. Educ. & Santa Maria & v. 6 & n. 13 & Set./dez. 2017 & p. 67-81 \\
\hline
\end{tabular}


sanitários, educacionais e políticos. Consideramos que a metodologia proposta mostrouse adequada e que a estrutura deste estudo poderá possibilitar um melhor entendimento da questão.

\section{Referências}

ALMEIDA, Antonio Augusto. A esclerectomia posterior no deslocamento da retina. São Paulo: USP, 1954. Tese (livre-doecência).Clínica Oftalmológica, Universidade de São Paulo.

ALMEIDA, Antonio Augusto. Compêndio de oftalmologia. Rio de Janeiro: Guanabara Koogan, 1974.

ALMEIDA, Antonio Augusto. Discurso como paraninfo da primeira turma de formandos da Faculdade de Medicina da Universidade de Campinas Campinas, 1968. Acervo Aqruivo Central da Unicamp/Siarq.

ALMEIDA, Márcio José de. Gestão da escola médica: crítica e autocrítica. Revista brasiselira de educação médica, v. 32, n. 2, 2008, p. 202-209.

BRUYNE, Paul de; HERMAN, Jacques; SCHOUTHEETE, Marc de. Dinâmica da pesquisa em ciências sociais: os polos da prática metodológica. Rio de Janeiro: Francisco Alves, 1977.

CUNHA, Miguel Pina e. Ciência organizacional: passado, presente futuro ou uma viagem dos clássicos aos pós-modernos. In: CUNHA, Miguel Pina e. Teoria organizacional: perspectivas e prospectivas. Lisboa: Dom Quixote, 2000, p. 47-65.

DIAS, Camila Delmondes; SILVA, João Luiz de Carvalho Pinto e; CRUZ, Maria Alice; SAAD, Mario José Abdall; FILHO PEREIRA; Rogério Antunes; PEREIRA, Rosa Ines Costa. FCM 50 anos: a realidade ultrapassou o sonho. Campinas: FCM/Unicamp, 2013.

DIAS, Emerson de Paula. Conceitos de gestão e administração: uma revisão crítica. REA, v. 1., n. 1, 2002, p. 1-12. Disponível em

<http://periodicos.unifacef.com.br/index.php/rea/article/view/160/16>. Acesso em 10.jul.2017

FERREIRA, Ademir Antonio. Gestão empresarial: de Taylor aos nossos dias, evolução e tendências da moderna administração de empresas. São Paulo: Pioneira, 1997.

FOUCAULT, Michel. A arqueologia do saber. Petrópolis: Vozes; Lisboa: Centro Luso Brasileiro, 1972.

FRANCO, Maria Estela Dal Pai; AFONSO, Mariangela Rosa; LUCIANE, Spanhol Bordignon. Gestão universitária: qualidade, investigação científica e inovação educacional. Revista G.U.A.L., v. 5, n. 1, 2012, p. 83-103.

GOMES, Eustáquio. O mandarim: a infância da Unicamp. Campinas: Unicamp, 2006.

GRILO, Rui Manuel Boleto. A teoria da gestão e a complexidade. Évora: EU, 1996. 114f. Monografia (trabalho de conclusão de curso de licenciatura em Gestão de Empresas). Universidad de Évora. Disponível em <http://www.manuelgrilo.com/rui/complexidade/trabalho.pdf>. Acesso em 11 set. 2013.

MASETTO, Marcos T. Gestão institucional da universidade. [powerpoint]. 2011. Disponível em <http://www.forumgestaoensinosuperior2011.ul.pt/docs_documentos/14/mtm.pdf>. Acesso em 2 fev. 2016. 
MORAES, Joysi; MARIANO, Sandra Regina Holanda; MACEDO, Alessandra Bellas Romariz de; MANEBO, Rafael Cuba. Uma proposição epistêmica quadripolar do constructo empreendedorismo. ENCONTRO DA ANPAD, 36, 2012. Anais ... Rio de Janeiro: $\quad$ Anpad, 2012. Disponível em <http://www.anpad.org.br/admin/pdf/2012_ESO1457.pdf>. Acesso em 15 dez. 2016.

OLIVEIRA, João Ferreira de; DOURADO, Luiz Fernandes. Programa escola de gestores da educação básica. Brasília: MEC, 2006, CD-ROM, 2a edição. Disponível em <http://escoladegestores.virtual.ufc.br/PDF/leitura4_sala7.pdf>. Acesso em 10 dez. 2016.

PAGLIOSA, Fernando Luiz; ROS, Marco Aurélio da. O relatório Flexner: para o bem e para o mal. Revista brassileira de educação médica, v. 32, n. 4, 2008, p. 492-499.

PEREIRA, José Carlos de Medeiros. A explicação sociológica na medicina social. São Paulo: Unesp; 2006.

REVISTA DA FACULDADE DE CIÊNCIAS MÉDICAS DA UNCIAMP. número especial comemorativo aos 30 anos de fundação da Faculdade de Ciências Médicas da Unicamp, maio 1993.

RIVERA, Francisco Javier Uribe; ARTMANN, Elizabeth. Planejamento e gestão em saúde: histórico e tendências com base numa visão comunicativa. Ciência e saúde coletiva, v. 15 , n. 5 , 2010, p. 2265-2274.

SANTOS, Elinado Leal; SANTOS, Reginaldo Souza; BRAGA, Vitor Lélio Braga V. L. Campo científico da administração: percursos e percalços. COLÓQUIO INTERNACIONAL DE EPISTEMOLOGIA E SOCIOLOGIA DA ADMINISTRAÇÃO, 4, 2014. Anais ... Florianópolis: UFSC, 2014, p. 1-27. Diponível em <http://coloquioepistemologia.com.br/site/wp-content/uploads/2014/04/ANE-124-OCAMPO-CIENT\%C3\%8DFICO-DA-ADMINISTRA\%C3\%87\%C3\%830.pdf>. Acesso em 10 jul. 2017.

UNIVERSIDADE ESTADUAL DE CAMPINAS / FACULDADE DE CIÊNCIAS MÉDICAS. Processo 01P-119/68. Relatório das atividades desenvolvidas pelo Departamento de Medicina Preventiva e Social no ano de 1968. 15p. 1968. - Processo 01P-119/68.

UNIVERSIDADE ESTADUAL DE CAMPINAS. Carvalho, Laerte Ramos, Casali, Alpinolo Lopes, Moreira, Aldemar, Santos, Jesus Marden dos, Batista FILHO, Olavo. Conselho Estadual de Educação: pedido de reconhecimento do Curso Médico da Universidade Estadual de Campinas, 18/02/1970, 7p. - Acervo Arquivo Central da Unicamp/Siarq.

UNIVERSIDADE ESTADUAL DE CAMPINAS. Estudo especial elaborado pelo professor Ademar Freire-Maia, instalações equipamentos e aspectos funcionais, anexo parecer $\mathrm{n}$. 23/70, fls. 16); 1970. - Acervo Aqruivo Central da Unicamp/Siarq.

UNIVERSIDADE ESTADUAL DE CAMPINAS. Processo n. 01P-1257/1968. Financiamento da URSS/BNDE - Acervo Arquivo Central da Unicamp/Siarq.

UNIVERSIDADE ESTADUAL DE CAMPINAS. Processo n. 01P-2779/1968. Financiamento da Polônia através do Ministério da Educação e Cultura - Acervo Aqruivo Central da Unicamp/Siarq.

UNIVERSIDADE ESTADUAL DE CAMPINAS. Relatório final da Comissão da Verdade e Memória Octávio lanni da Unicamp. Campinas, $1^{\circ}$ abr. $2015 . \quad$ Disponível em <http://www.unicamp.br/unicamp/sites/default/files/field/arquivo/relatorio_final_cvm.pdf>. Acesso em 20 dez. 2016. 
Ivan Luiz Martins Franco do Amaral é assistende administrativo no Centro de Memória e Arquivo da Faculdade de Ciências Médicas da Unicamp e estudante do curso de mestrado em Saúde Coletiva na mesma instituição.

Endereço: Rua Tessália Vieira de Camargo, 126 - 13083-887 - Campinas - SP Brasil.

E-mail: ivanfa@fcm.unicamp.br.

Everardo Duarte Nunes é doutor em Ciências e professor colaborador do Departamento de Saúde Coletiva da Faculdade de Ciências Médicas da Unicamp. Endereço: Rua Tessália Vieira de Camargo, 126 - 13083-887 - Campinas - SP Brasil.

E-mail: evernunes@uol.com.br.

Recebido em 11 de julho de 2017.

Aceito em 15 de agosto de 2017. 